\title{
POR UMA HISTÓRIA DA SEXUALIDADE ENTRE FREUD E FOUCAULT: COSTURAS E ALINHAVOS
}

\author{
Maria de Fátima Pessoa de ASSIS ${ }^{1}$ \\ Maria Lúcia de OLIVEIRA ${ }^{2}$
}

\begin{abstract}
RESUMO: O presente artigo apresenta como objetivo abordar a temática da sexualidade na atualidade a partir das contribuições de Sigmund Freud e Michel Foucault. Trata-se de uma pesquisa bibliográfica, que derivou de experiências de trabalho no âmbito da pesquisa, do ensino e da extensão. Os resultados revelam que a aproximação entre Freud e Foucault torna-se importante por nos fazer ver as determinações históricas da sexualidade. Este estudo apresenta como conclusão a idéia de que embora existam diferenças entre estes autores no tratamento do tema da sexualidade, uma aproximação entre os mesmos é extremamente elucidadora para compreendermos os diferentes sentidos e significados que envolvem o debate sobre a sexualidade no contexto atual.
\end{abstract}

PALAVRAS-CHAVE: Sexualidade. Psicanálise. Contemporaneidade.

\section{Introdução}

Neste artigo, procura-se abordar a temática da sexualidade na atualidade, cotejando-a a partir de Sigmund Freud e Michel Foucault. As reflexões apresentadas derivam de experiências de trabalho no âmbito da pesquisa, do ensino e da extensão, em cursos de formação de pedagogos e psicólogos. Em todos estes contextos, buscamos investigar como podemos compreender a sexualidade na contemporaneidade a partir de suas determinações históricas, sócio-culturais, antropológicas e psicossociais.

A aproximação entre estes dois autores revelou-se problemática, uma vez que o que estava em jogo eram as diferentes abordagens da sexualidade: em Freud encontra-se a hipótese repressiva enquanto que em Foucault o foco é a analítica do poder.

O trabalho de costurá-los mostrou-se árduo, embora profícuo para encaminharmos uma discussão sobre a sexualidade na contemporaneidade.

Para que possamos situar o trabalho de Foucault sobre a história da sexualidade e estabelecermos uma interlocução/ aproximação com a Psicanálise, faremos, de forma

\footnotetext{
${ }^{1}$ UFG - Universidade Federal de Goiás. Departamento de Psicologia. Jataí - GO - Brasil. 75.804-020 mafapessoa@yahoo.com.br

${ }^{2}$ UNESP - Universidade Estadual Paulista. Faculdade de Ciências e Letras - Departamento de Psicologia da Educação. Araraquara - SP - Brasil.14800-901 - luciaeguimar@yahoo.com.br
} 
introdutória, uma explicitação da perspectiva histórica e metodológica adotada por este autor. Em um segundo momento, discutiremos a abordagem psicanalítica da sexualidade e para finalizar, apresentamos uma proposta de conexão entre estes dois autores.

\section{A concepção de história em Foucault}

Barbosa (2004), ao propor uma análise do conceito de história que norteia as obras de Foucault, nos mostra que este autor procurou situar-se em relação às diferenças entre a História Tradicional e a História Nova do contexto da historiografia francesa de sua época. Na primeira, trata-se de reconstituir o rosto de determinado período, supondo haver um sistema de relações homogêneas configurando-se como uma rede de causalidade entre todos os acontecimentos de uma área espaço-temporal. A tarefa do historiador consiste, nesta ótica, em traçar as linhas de continuidade do desenvolvimento de um pensamento, em uma lógica evolutiva.

Em confronto com esta perspectiva, o trabalho de Foucault visa a construção de múltiplos centros de estruturação e dispersão, buscando evidenciar não a continuidade e a linearidade, mas a pluralidade de sentidos. Para tanto, seria necessário ver a história como uma genealogia, que se pauta pela descontinuidade, como na abordagem da Nova História. Esta última, ao eleger os recortes, os limites, os níveis e os deslocamentos, problematiza o espírito de causalidade das abordagens tradicionais, erigindo-se como uma história descontínua, tal como propõe Barbosa (2004).

A perspectiva de enfatizar a descontinuidade na história, dirige nosso olhar para a formação de um novo regime no discurso e no saber. Busca-se a trama histórica, em vez de resolver os problemas de constituição histórica em termos de uma "origem” ou de um "sujeitoorigem”, pois as descontinuidades vão além das individualidades, enredando-se como instâncias que nos atravessam, conformando saberes, práticas e discursos. Sob este ângulo, abre-se caminho para uma nova sensibilidade histórica, que, ao contrário de valorizar os heróis da história ou a vontade de um soberano, valorizam-se as práticas sociais de homens anônimos que escrevem a história:

Há anos os historiadores ficaram muito orgulhosos quando descobriram que podiam fazer não somente a história das batalhas, dos reis e das instituições, mas também a história da economia. Ei-los todos estupefatos por terem os mais 
maliciosos dentre eles mostrado que também se podia fazer a história dos sentimentos, dos comportamentos, dos corpos. (FOUCAULT, 1993, p.230)

Para Foucault (1993), somente poderíamos ter acesso ao homem pela vida, pelo trabalho e pela linguagem, ou seja, somente é possível conhecê-lo pelo que ele é, produz e diz. Sob este prisma, o sujeito é tecido nos enunciados científicos, uma construção historicamente determinada pelas práticas discursivas. Portanto, ele não é um dado já inscrito na origem, naturalizado, mas destino e produção. O que norteia a arqueologia dos saberes sobre o humano é a ótica das tecnologias de si ou formas de subjetivação. É nesta perspectiva que empreende a história da sexualidade. Esta última é vista como efeito produzido nos corpos, nos comportamentos e nas relações sociais por um dispositivo complexo:

[...] a sexualidade é o nome dado a um dispositivo histórico [...] à grande rede de superfície em que a estimulação dos corpos, a intensificação dos prazeres, a incitação ao discurso, a formação dos conhecimentos, o reforço dos controles, das resistências, encadeiam-se uns aos outros, segundo algumas estratégias de saber e poder. (FOUCAULT, 1993, p.100).

Com o advento da modernidade e o nascimento das ciências modernas, surge a scientia sexualis, que vai diferenciar-se da arte erótica da antigüidade. O discurso científico, ao agregar saber e poder, produz efeitos de verdade. Interessa particularmente a Foucault como o poder que se exerce sobre a sexualidade produz o discurso verdadeiro sobre esta: “[...] no Ocidente trata-se do discurso científico. Foi sob este ângulo que quis abordar a sexualidade.” (FOUCAULT, 1993, p.258).

A partir das relações de poder agenciadas pelo discurso científico, nasce no século XVII a valorização do corpo como objeto de saber e elemento de poder. No tocante à sexualidade faz-se necessário pesquisar os efeitos de verdade decorrentes do discurso científico sobre a sexualidade, tarefa do historiador.

\section{A história da sexualidade}

Partindo do objeto de estudo sexualidade na contemporaneidade, Foucault (2001, 2002, 2003), empreende sua genealogia, buscando as múltiplas causalidades imbricadas em diferentes temporalidades. Como historiador do presente, este autor persegue nos discursos, práticas, 
realidades e instituições como a sexualidade vai se constituindo e se disseminando na forma de um dispositivo no corpo social.

Nesta busca, percorrendo tramas históricas, nos mostra que durante o período helenístico (nos séculos que precederam ao cristianismo, bem como nos dois primeiros da era cristã), ainda não podemos observar as idéias de "sexualidade” e "sexo", mas uma “aphrodisia”, o regime que rege os atos e os prazeres, uma arte erótica. Nesta, o exercício do prazer encontra-se atrelado a uma reflexão ética cujo problema não é saber quais são os atos permitidos ou proibidos, mas com que força se é levado pelos prazeres e desejos. Trata-se de uma questão de cálculo, de reflexão, de buscar os modos pelos quais se distribuem e se controlam os atos; os aphrodisia se configuram como um campo de cuidados morais no qual o exercício da sexualidade não carrega em si um mal ou decadência, mas são considerados como algo natural e indispensável.

Embora não sendo um mal, pedem uma delimitação para fixar até que ponto é conveniente praticá-los. O uso dos prazeres é constituído em função de diferentes estratégias que permitam obter prazer como convém. A enkrateia ou "temperança” revela-se como um trabalho sobre si mesmo para a obtenção da liberdade: “[...] ser livre em relação aos prazeres é não estar a seu serviço, é não ser seu escravo.” (FOUCAULT, 2003, p.74).

A partir dos meandros da Idade Média, com a instauração da problemática da carne e após o Concílio de Trento, o sacramento da confissão intensifica-se e com ele surge a polícia da língua. A carne passa a ser a origem de todos os pecados e o desejo um mal que atinge todos os homens. O séc. XVII faz emergir uma constrição geral no ocidente moderno, a tarefa de dizer, de forma infinita, a si e aos outros tudo o que possa estar relacionado com o jogo dos prazeres, mas agora, pelo crivo do dispositivo de sexualidade, complexa rede que congrega saber e poder, erigida pela burguesia em ascensão.

Por intermédio do dispositivo de sexualidade, a burguesia assume um corpo e uma sexualidade próprios, afirmando sua diferença e sua hegemonia no séc. XIX. Neste momento podemos verificar um paradoxo: uma intensa repressão e ao mesmo tempo, uma grande obstinação em fazer falar o sexo. Para elucidar os fatores em jogo nesta trama, seria preciso não limitar-se à hipótese da repressão da sexualidade, recolocando-a em uma economia geral dos discursos.

Em “a vontade de saber” Foucault (2001) passa a estudar a história da sexualidade em termos de jogos de poder e de verdade, trabalho no qual podemos perceber a instauração, a partir 
do séc. XIX, de uma "ciência confissão" com seus procedimentos para fazer falar o sexo em termos de uma codificação clínica que estabelece os parâmetros para o normal e o anormal no campo da sexualidade. Aparecem, então, personagens novos: "a mulher nervosa”, a "esposa frígida”, a "moça histérica”, o “marido impotente”.

Para Foucault (2001), a sexualidade burguesa, comparada às demais é marcada pela repressão intensa, apresentando-se como modelo para todas as camadas sociais. A sexualidade passa a ser vista como a chave para a compreensão da individualidade, ou melhor, o que constitui a própria individualidade. A partir do séc. XIX, o dispositivo de sexualidade vai fixando-se na forma da família, lugar obrigatório do afeto e dos sentimentos de amor.

A célula familiar recebe uma intensificação na sua valorização, desde o séc. XVII, em duas direções: o eixo pais e filhos e o eixo marido-mulher. Emerge toda uma teorização médica em torno do corpo feminino, da precocidade da sexualidade infantil, da regulação dos nascimentos e da especificação dos atos perversos. Portanto, o papel da família é o de fixar a sexualidade e, ao fixá-la, constituir o seu suporte permanente.

Neste espaço de manobras e no final do século XIX, instala-se a Psicanálise, que vem ampliar o conceito de sexualidade até então restrito à abordagem neurológica.

Para Foucault, a história do dispositivo de sexualidade, a partir da modernidade pode valer como arqueologia da Psicanálise. A Psicanálise:

[...] desempenha vários papéis simultâneos nesse dispositivo: é mecanismo de fixação da sexualidade sobre o sistema de aliança; [...] funciona como elemento diferenciador na tecnologia geral do sexo. Em torno dela, a grande exigência da confissão que se formara há tanto tempo, assume um novo sentido, o de uma injunção para eliminar o recalque. (FOULCAULT, 2001, p.123).

A Psicanálise emerge como saber médico para tratar as chamadas "doenças nervosas", constituindo-se como terapêutica frente às demandas de ajuda da família burguesa que sofre os efeitos da intensificação da repressão, produzida pelo dispositivo de sexualidade.

\section{A sexualidade na perspectiva psicanalítica}

Para a Psicanálise, a sexualidade é constitutiva da subjetividade humana, considerada como estrutura construída no seio de experiências intersubjetivas. Caracteriza-se por não limitar- 
se às atividades de prazer que dependem do aparelho genital, envolvendo toda uma série de excitações e atividades presentes desde a infância, nas atividades de sucção do lactente, na retenção e expulsão de excrementos, nos exibicionismos, entre outras. Podemos falar de um corpo infantil que vai se tornando erotizado pelo investimento de energia libidinal nas diferentes zonas erógenas: oral, anal e genital.

A Psicanálise nos fala, portanto, não de uma sexualidade limitada ao corpo biológico, mas produzida pelas experiências psíquicas inconscientes, uma psicossexualidade. A grande contribuição da psicanálise foi nos revelar a lógica do inconsciente:

É evidente que o corpo psicanalítico é um corpo fantasmático e não um corpo anátomo-fisiológico. Mesmo quando Freud articula a sexualidade às necessidades básicas do indivíduo, quando "apóia” a pulsão no instinto, não é para a semelhança entre ambos que está apontando, mas sim para as suas diferenças. [...] É para o fantasma que se dirige o desejo e não para o real; é ao nível da representação que se passa a psicanálise. (GARCIA-ROZA, 2003, p.102).

A hipótese central da psicanálise é a repressão, ou seja, o inconsciente estrutura-se na base da repressão da sexualidade, cujos conteúdos, muitas vezes considerados insuportáveis por força da repressão, são assim mantidos fora do campo da consciência.

Para a Psicanálise, há um vínculo entre a sexualidade e a produção de neuroses e outras doenças psíquicas na vida adulta, ou seja, as neuroses surgem como defesa contra a sexualidade infantil que ameaça romper-se. Os conteúdos psíquicos ligados à sexualidade sofrem a ação da censura, exemplificada, externamente, nos fatores restritivos da civilização, que limitam as manifestações da sexualidade.

De acordo com Freud (1986) a civilização ergueu-se com base na repressão da sexualidade e na canalização da energia libidinal para outras atividades artísticas e culturais, via processo sublimatório: “[...] a sublimação do instinto constitui um aspecto particularmente evidente do desenvolvimento cultural; e é ela que torna possível as atividades psíquicas superiores, científicas, artísticas e ideológicas, o desempenho de um papel tão importante na vida civilizada.” (FREUD, 1986, p.118).

Os processos repressivos nos conduzem ao mal-estar na civilização, uma vez que nem toda a libido conseguiria escoar-se pela via sublimatória, restando uma boa parcela sendo sacrificada em sua expressão pela repressão, que apresenta-se difusa nas variadas demandas do 
processo civilizatório: educação, leis, regras, normas, etc., fazendo com que a vida sexual do homem civilizado encontre-se severamente prejudicada.

Em seu trabalho “arquivos do mal-estar e da resistência”, Birman (2006), nos alerta para o risco de empreendermos uma leitura do texto freudiano “o mal -estar na civilização” (FREUD, 1986), de maneira abstrata e a-histórica vendo neste, apenas uma passagem da espécie humana do registro da natureza para a ordem da cultura. Sob este prisma, o mal-estar seria naturalizado, concebido como o preço a se pagar pela condição humana, condenada eternamente aos impasses produzidos pelo conflito entre a natureza e a cultura.

As marcas antropológicas da subjetividade são históricas e nesta perspectiva, o mal-estar não pode ser analisado em termos de um conflito universal e a-temporal, mas produzido pela modernidade, cujos efeitos foram devastadores para a subjetividade.

Se nas sociedades tradicionais hierarquizadas, típicas do período medieval o projeto identificatório era relativamente fixo, pois dado anteriormente pela referência central em um pai soberano, origem de tudo e que a todos protegia; com a modernidade, esta estabilidade do referente simbólico paterno se perde, lançando as subjetividades na condição de desamparo.

Assim, o sujeito na modernidade deve produzir-se por seus próprios meios, mediante uma construção laboriosa de si mesmo que envolve escolhas no cenário de uma pluralidade de possibilidades identificatórias. Não há mais uma fronteira única que forneça segurança ao sujeito, ficando entregue à própria angústia.

É neste quadro histórico que o mal-estar deve ser compreendido, como um "mal-estar na modernidade”, posto que tanto a idéia de civilização quanto a barbárie dela decorrentes foram construções da modernidade. Nas palavras de Birman (2006, p.2006, p.377):

[...] a história de cada um de nós, no que tem de mais íntima e singular, é marcada não apenas pelos traços produzidos por nossa biografia, estabelecida na temporalidade de nossa existência, mas se abre também para o imaginário coletivo, que como tradição simbólica, nos constitui efetivamente.

A interpretação freudiana da subjetividade que a concebe dividida, descentrada e em conflito entre o pólo normatizador e o pólo transgressor dos desejos, encontra-se também inscrita nas contradições e paradoxos da modernidade. Neste contexto, conforme esclarece Birman (2006), o inconsciente sexual descrito pela psicanálise foi historicamente construído. 
Para Birman (2006) Freud e Lacan revelaram como o inconsciente foi permeado pelos valores do patriarcado. Como exemplo, podemos citar as primeiras teorizações freudianas referentes ao "masculino" e "feminino" (ter o falo/não ter o falo; “a inveja do pênis nas meninas").

Enfim, para que a psicanálise continue fecunda para pensar o mal estar na cultura e na contemporaneidade, problemática que passa, a nosso ver, necessariamente pela economia erótica das subjetividades, faz-se necessário uma leitura da mesma em uma perspectiva histórica. Uma aproximação entre Freud e Foucault torna-se extremamente elucidadora na abordagem da sexualidade nos tempos atuais.

\section{Freud e Foucault: costuras e alinhavos}

Para Foucault (2002), a Psicanálise ocupou uma posição singular no final do séc. XIX, pois representou uma ruptura com o sistema teórico da degenerescência, separando a tecnologia médica do instinto de suas correlações com a hereditariedade e com todos os racismos e eugenismos. Assim, em meio às injunções do bio-poder, que culminou em direções problemáticas como o nazi-facismo, com seu ideário de "proteger a pureza do sangue e fazer triunfar a raça”, a Psicanálise, ao romper com as teorias da neuropsiquiatria e da degenerescência, vai representar política e teoricamente o extremo oposto do nazismo.

Até os anos setenta, conforme observa Birman (2000), Foucault mantém uma interlocução de caráter mais conciliatório com a Psicanálise, vendo neste saber uma forma de rompimento com a filosofia do sujeito iluminista, que colocava a afirmação da subjetividade inteiramente na razão.

A idéia preconizada por Freud de que as ações humanas estão implicadas em determinações inconscientes, representou, para Foucault, a inauguração de um saber subversivo, com um grande potencial transgressor face aos pensamentos científicos hegemônicos. Mas, ao analisar a lenta implantação da sexualidade na forma de um grande dispositivo de poder e controle inerente à burguesia, que passa a investir maciçamente no corpo e na sexualidade, a Psicanálise passa a ser vista como mais um jogo de verdade resultante dos agenciamentos produzidos pelas estratégias de poder. Instala-se, portanto, a partir dos estudos sobre a analítica 
do poder, uma interlocução de caráter mais crítico de Foucault em relação à Psicanálise, que esta última terá de enfrentar, se quiser manter uma interlocução fecunda com este autor.

Para Birman (2000), é preciso que a Psicanálise coloque em questão o imperativo platônico-socrático do conhecer a si mesmo para que possa inscrever-se na tradição ética do cuidado de si, concebendo a linguagem de outra maneira, como algo inscrito no campo de relações de força, ou seja, o olhar do psicanalista deve voltar-se também para as relações de poder veiculadas na linguagem.

A linguagem como lugar do Outro, do Simbólico, que inscreve a falta, deve também ser vista como matriz dos jogos de verdade, perpassada pela intensidade das forças contidas na microfísica do poder, de acordo com Birman (2000).

Para que a Psicanálise continue fecunda para pensar o mal-estar na modernidade tardia, acreditamos que esta deve manter a sua ética, calcada na premissa de que não se deve renunciar ao desejo inconsciente, mesmo que isto coloque o sujeito em confronto com o poder disciplinar que nos dita os agenciamentos de nossa histórica subjetividade.

Para manter a positividade de seu caráter subversivo, o saber psicanalítico deve radicalizar o seu rompimento com a filosofia do sujeito centrado na vontade de saber e vontade de verdade, que nos remete ao grande peso dos saberes científicos na regulamentação de nossas vidas. Pois, se a Psicanálise limitar-se a permanecer reclusa em uma perspectiva de trabalho que visa apenas a codificação da fala em termos de uma racionalidade científica, ela perde o seu caráter subversivo e se iguala à Psicologia e `a Psiquiatria como versões de saberes e práticas disciplinares.

No tocante à temática da sexualidade, a Psicanálise não pode fazer vista grossa para a dimensão planetária da ação do bio-poder, regimentado pelo capitalismo tardio da contemporaneidade, que lança os corpos no circuito das mercadorias, transformando-os em objetos cultuados, que envolvem enormes investimentos de tempo e dinheiro.

De fato, conforme observa Kehl (2002), a Psicanálise deve tomar parte na empresa de criação do sujeito como autor de si mesmo, que antes de mais nada, é autor de sua própria fala. A mesma linguagem que nos agencia no sentido dos poderes instituídos, é veículo de expressão de nossos desejos inconscientes que marcam nossa singularidade e diferença, irredutíveis à norma. 


\section{Considerações finais}

Tanto a contribuição de Foucault, quanto de Freud nos permitem vislumbrar possíveis saídas para os impasses do mal estar na contemporaneidade, principalmente quando nos mostram as possibilidades de resistência aos poderes instituídos e disseminados.

Tomando-se alguns pontos para um debate entre estes dois autores, e na perspectiva de situar o sujeito frente às contradições do capitalismo tardio, é necessário evitar uma leitura simplista das obras de Foucault e de Freud que nos possa levar a perceber as pessoas como meras criaturas de alguma maquinaria social de poder ou regidas mecanicamente pelas forças do inconsciente. Neste aspecto, concordamos com Sahlings (2006), para quem o processo de aculturação dos sujeitos não pode ser visto como sinônimo de subjugação. Embora a cultura seja fortemente investida de poder, ela nunca é repressiva de forma monolítica de modo a não restar nenhum espaço para a singularidade do sujeito. A linguagem, lugar do Outro, chega ao sujeito por intermédio de uma psique única, que interage com esta de maneira negociável, isto é, frente aos diferentes sentidos e significados postos pela cultura, cada um dá às estruturas de poder a unidade de sua pessoa, a partir de sua biografia particular e de suas vivências institucionais, em dado momento da história que pode viver e contar.

\section{INTERACTIVITY IN VIRTUAL LEARNING ENVIRONMENT: CONTRIBUTIONS OF AN EXPERIENCE}

ABSTRACT: The relationship between man and technology - in which the rules are constantly being discussed - the humanization of technology is the component that can guarantee the social appropriation of technology. This humanization may be achieved as the technology is transforming the communication process and, therefore, is to contribute to the growth and educational development of man. We talk, therefore, in communication technologies - ie technologies that lend themselves to facilitate the communication process between the subjects. In the context of mediated communication, computer and Internet are capable of allowing a kind of social environment mediated and thus also end up enabling the man may experience an immersion in a virtual environment for communication. Joining the possibilities offered by virtual environments, the growing need for continuing education in the setting of learning society, formed the setting for the development of Virtual Learning Environments (VLE). As information technology and communication develop, so the virtual learning environments advance, since they embody the technological potential of society. This article examines, through studies of interactivity, the interactional behavior of subjects immersed in VLE as a support for educational development. 
KEYWORDS: Virtual learning. Environment. Interaction. Interactivity.

\section{REFERÊNCIAS}

BARBOSA, P. L N. O acontecimento discursivo e a construção da identidade na história.In: SARGENTINI, V.; BARBOSA, P. L. N. (Org). Foucault e os domínios da linguagem: discurso, poder, subjetividade. São Carlos: Claraluz, 2004. p.97-130.

BIRMAN, J. Arquivos do mal-estar e da resistência. Rio de Janeiro: Civilização Brasileira, 2006.

Entre o saber e o cuidado de si: sobre Foucault e a Psicanálise. Rio de Janeiro:

Relume-Dumará, 2000.

FOUCAULT, M. História da sexualidade: o uso dos prazeres. Rio de Janeiro: Graal, 2003. v.2.

História da sexualidade: o cuidado de si. Rio de Janeiro: Graal, 2002. v.3.

História da sexualidade : a vontade de saber. Rio de Janeiro: Graal, 2001. v.1.

. Microfísica do poder. Rio de Janeiro: Graal, 1993.

FREUD, S. Moral sexual civilizada e doença nervosa moderna. In: Obras completas.

Rio de Janeiro: Imago, 1986. v.9.

GARCIA-ROZA, L. A. Freud e o inconsciente. Rio de Janeiro: J. Zahar, 2003.

KEHL, M. R. Sobre ética e psicanálise. São Paulo: Companhia das Letras, 2002.

SAHLINGS, D. M. História e cultura: apologias a Tucídides. Rio de Janeiro: J. Zahar, 2006. 